cultures with 500-1,000 $T C D_{50}$ per $0.1 \mathrm{ml}$. of Coxsackie $A-9$ virus failed to reveal the presence of such agents. Two additional sub-passages yielded similar results as did a single test performed in rabbit kidney cell monolayers according to the technique reported by MeCarthy, Taylor-Robinson and Pillinger ${ }^{11}$. Suckling mice and chicken embryonated eggs were inoculated with the vaccine, also. Tests for detection of viable microbes other than viruses were similarly negative.

The results of virus isolation investigations indicate that the frequency of rubella virus isolation was greater from throat washings collected 1-12 rather than $13-24 \mathrm{~h}$ after rash onset. From 30 clinically diagnosed cases of rubella, 18 rubella virus isolates were obtained: 10/12 (83 per cent) from throat washings collected $1-12 \mathrm{~h}$ and 8/18 (44 per cent) from specimens collected $13-24 \mathrm{~h}$ following onset of rash. Rubella virus was recovered from 1 of 14 'rubella contacts' and rubeola virus from 2 individuals with illnesses clinically diagnosed as measles. Each rubella virus isolate was further characterized in that: (1) none was neutralized by homologous- or heterologous-acute phase serum samples but each was crossneutralized by 3 -week convalescent sera (antibody titres $1 / 32-1 / 512) ;(2)$ the infectivity of each isolate was neutralized by 4 pools of human $\gamma$-globulin $\uparrow$ (antibody titres 1/128-> 1/512); (3) each was neutralized by a standard reference rubella virus antiserum‡ (antibody titres $1 / 16-1 / 1,024) ;(4)$ all the convalescent but none of the acute phase serum samples neutralized a standard reference rubella virus preparation $\ddagger$ (antibody titres 1/64-1/1,024). Various virus hyperimmune antisera failed to react with any of the isolates in neutralization and complement-fixation tests. Based on these results, the rubella virus isolates appeared to be antigenically similar to, or identical with, one another and the reference rubella virus preparation.

To determine whether the vaccine would induce the formation of neutralizing antibodies, 11 male guinea-pigs weighing 600-700 $\mathrm{g}$ were injected intramuscularly with $1.0 \mathrm{ml}$. $(0.5 \mathrm{ml}$. injected into each of 2 sites $)$ of vaccine and serum was collected at intervals noted in Table 1. Two additional animals as controls were inoculated with $1.0 \mathrm{ml}$. of normal tissue culture fluid treated with ethylene oxide. Neutralizing antibody titres were determined in a single ne'titralization test employing rubella virus isolate $G L 8$

† Kindly supplied by Dr. J. Inman, Ortho Research Foundation, Raritan. Now Jersey.

$\ddagger$ Kindly supplied by I)r. G. Schiff, University of Cincinnati Medical School. rather than $G L 6$ used in the preparation of the vaccine'. It can be seen from Table 1 that neither pre-vaccination sera nor serum specimens collected 1. week following a single injection of vaccine contained rubella virus anti. bodies. One week after a second injection of vaccine, neutralizing antibody titres were detected in 3 of 6 guineapig sera (antibody titres $1 / 32-1 / 64$ ). Significantly higher titres $(1 / 32-1 / 512)$ were found in serum samples collected 1 week after a third inoculation of vaccine (geometric: mean 1/34) and these titres appeared to decline within 10 weeks (geometric mean 1/11). However, a single injection of vaccine at this 10 -week interval resulted in an increase in the geometric mean of the neutralizing antibody titres to $1 / 60$. Moreover, this additional inoculation resulted in the seroconversion of one guinea-pig (No. 6). Antibodies were not detected in undiluted serum samples collected from another (No. 3). None of the sera collected from immunized and control animals neutralized Coxsackie $A .9$ virus.

The results of these investigations indicate that rubella virus neutralizing antibodies appear in sera of guinea-pigs following immunization with rubella virus vaccine not containing detectable viable rubella virus. Since infection with rubella virus may result in serious congenital malformations, the results suggest that vaccination of susceptible human beings with non-viable rubella virus vaccine may induce the formation of antibodies protective against this virus infection.

I thank Captain I. F. Miller (U.S.N.), Lieut. J. Maisel (U.S.N.R.), Dr. R. E. Jewett (University of Kansas Medical School), Mr. A. E. Cadilek (CIBA), Mr. O. F. Andersen (CIBA) and Mr. N. F. McHugh (CIBA) for their assistance.

'Parkman, P. D., Buescher, E. L., and Artensteil, M. S., I'roc. Soc. Exp Biol. and Med.,111, 225 (1962).

'Sever, J. L., Schiff, G. N., and Trauh, R. G., J. Amer. Med. Assoc., 182 663 (1962).

${ }^{3}$ Weller, T. H., and Neva, F. A., Proc. Soc. Exp. Biol. and Med., 111, 21:; (1962).

4 Veronelli, J. A., Maassab, H. F., and Hennessy, A. V., Proc. Soc. Exp. Biol. and Med., 11i, $472(1962)$

'Sigurdardottir, B., Givan, K. G., Rozee, K. R., and Rhodes, A. J, . Canac'. Med. A880c. $J_{\text {., , 88, } 128 \text { (1963). }}$

${ }^{6}$ Plotkin, S. A., Dudgeon, J. A., and Ramsay, A. M., Brit. Med. I., ii, 1296 (1963).

? Lehmann, N. I., and Ferris, A. A., Med. J. Austral. 25, 1015 (1963).

${ }^{3}$ Forbes, J. A., Bennett, N. McK., and Gray. N. J.. Med. J. Austial., 25, 1016 (1963)

- Selzer, G., Lancet, Ii, 336 (1963).

${ }^{10}$ Heggie, A. D., and Robbins, F. C., Pror. Soc. Exp. Biol. and Med., 114. 750 (1963).

"MeCarthy, K., Taylor-Robinson, C. H., and Jillinger, S. F., Lencet. ii $593(1963)$.

\title{
RELATIONSHIP BETWEEN RADIATION DOSE AND GIANT CELLS IN THE SURVIVING CELL POPULATION OF MOUSE MARROW AS DETERMINED BY INTERFERENCE MICROSCOPY
}

\author{
By HUN LEE and Prof. VICTOR RICHARDS
}

\author{
Department of Surgery, Presbyterian Medical Center, San Francisco
}

$\mathrm{W}$ E have reported previously the dry mass distribution of the normal bone marrow cell population of the inouse ${ }^{1}$ and the subsequent changes during the first 24-h post-irradiation period ${ }^{2}$, and suggested that the dry mass changes might help to determine the degree of radiation injury of the marrow and the chances of survival of the patient. This article is the result of an investigation of the quantitative relationship between radiation doses and the changes in cellular dry mass of the giant cells in the surviving marrow cell population $24 \mathrm{~h}$ following irradiation. The changes, as we observed, are approximately proportional to the radiation dose; thus the information may be of value in the estimation of radiation injury to the marrow caused by a source known or unknown as to its strength.

$L A F_{1}$ male mice of approximately $20-33 \mathrm{~g}$ body-wt. and about 8-9 weeks of age were supplied by Jackson Memorial Laboratory. Each animal was exposed to a single dose of total-body $\mathrm{X}$-irradiation $(200 \mathrm{kVp}, 20 \mathrm{~m}$.amp. high-voltage layer, $1.35 \mathrm{~mm}$ coppor) in an individual plastic container. Some of these doses, namely, 1,000 and $1,500 \mathrm{r}$., were composed of two successive exposures with an interval between them of no more than $10 \mathrm{~min}$. Twenty-four hours after the irradiation, the animal was 
killed in a glass jar with an overdose of ether. Slide preparations for interference microscopy were made from the femoral marrow cells suspended in normal saline. The techniques of slide preparation and interference microscopy were described in our previous publications $\mathbf{1}^{\mathbf{1 , 3 , 4}}$.

Two thousand cells from 40 non-irradiated control animals and 1,000 cells from 20 irradiated animals for each of the following $\mathrm{X}$-radiation doses were measured for their total cellular dry mass with the aid of an $A-O$ interference microscope and a half-shade eyepiece. The doses tested were: $100,200,300,400,500,600,700,800$, $900,1,000$ and $1,500 \mathrm{r}$. Of 50 cells from each animal, 25 from each femur were measured. The megakaryocytes, which were too variable in size and often difficult to measure because of the difference in dry mass concentrations between cytoplasm and nucleus, coupled with the irregularity in the shape of the nucleus, and cells smaller than the mature neutrophiles (about 8-10 $\mu$ in average diameter when flattened in the slide preparation), which include the erythrocytes, small lymphocytes and small nucleated erythrocytes, were excluded from measurement. The erythrocytes, the small lymphocytes and the small nucleated cells in the erythrocyte series were found without discernible change in dry mass following lethal irradiation in our previous experiments. The mature granulocytes, which also showed little or no change in dry mass, however, were included in our measurements because we needed a base line for calculating the percentages of giant cells. Except for the excluded cell types mentioned above, all the cells found in each microscopic field of a $100 \times$ objective were measured. By and large there were only a few cells in each field, as the cells must be well separated for interference microscopic measurements. To find 25 measurable cells from a single slide, it must have an average of 5-10 fields, thus for 1,000 cells as many as 200-400 microscopic fields were needed. This provided satisfactory compensation for the lack of uniform distribution of different types of cells in the marrow.

We chose to study the post-irradiation period at the 24-h level because we found that the maximum dry mass increase in the marrow cells was reached at the end of that period ${ }^{2}$.

As we have already stated, our main interest in this work is the quantitative relationship between radiation doses and the changes in the giant cells of the surviving marrow cell population. The death of the giant cells which may occur at higher dose-levels, and their rate of death are, however, not included in our study. This relationship is three-fold: (1) the distribution of giant cells, of different dry mass values in the surviving population; (2) the changes in mean dry mass per cell of the surviving giant cell population; (3) the changes in percentages of giant cells in the surviving cell population, as related to radiation doses. A giant cell is arbitrarily defined as any cell which has a total dry mass of more than 110 relative units, with the exception of megakaryocytes which were excluded from our measurements. The line of demarcation was drawn at 110 relative units due to the fact that, with the exception of megakaryocytes, only 0.1 per cent of the normal marrow cells reached the dry mass level between 110 and 130 relative units among 2,000 cells measured in our non-irradiated control animals, and none was found beyond this limit. The demarcation line could more appropriately set at 130 relative units had it not been for the fact that the percentage of cells between 110 and 130 relative units in dry mass increased rapidly as the radiation dose increased even at the non-lethal levels where no evidence of cell death was found. These cells must be considered as radiation-induced giant cells as well as the cells with more than 130 relative units of dry mass.

Distribution of giant cells of different dry mass values in the surviving cell population. As aforementioned, in the non-irradiated controls we found only $0 \cdot 1$ per cent of cells which had a dry mass value between 110 and 130 units

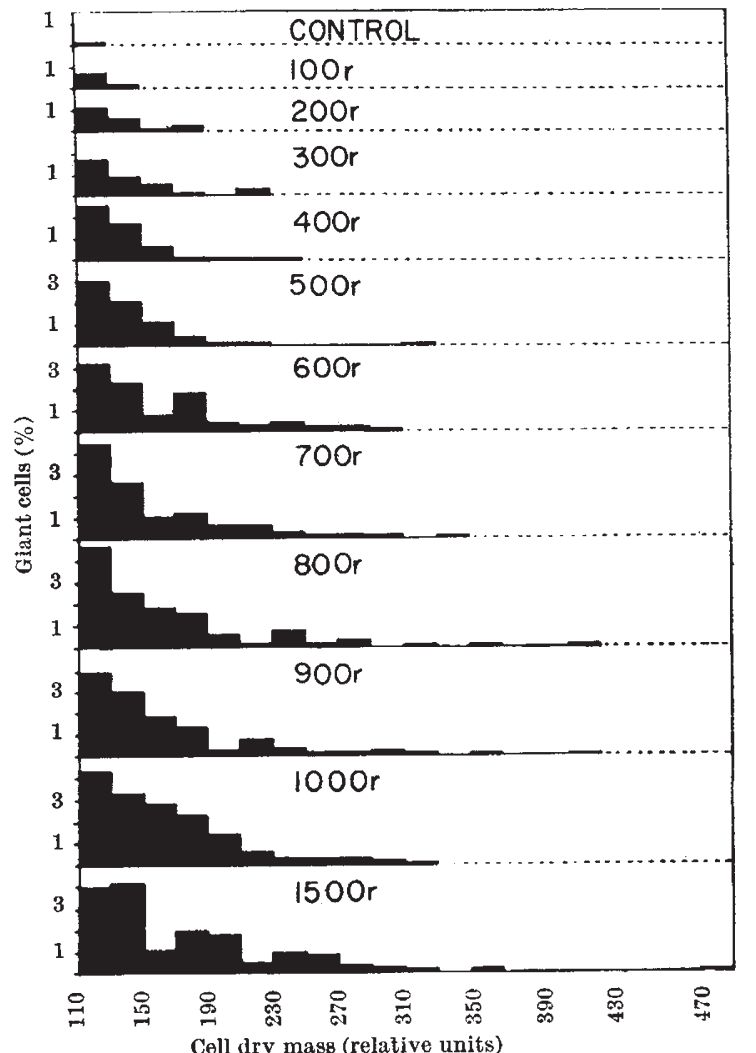

Fig. 1. Distribution of giant cells in mouse marrow cell population according to their dry mass values. Except for megakaryocytes, all the cells with more than 110 relative units in dry mass are ccnsidered as giant cells. The percentages of giant cells and their dry mass ranges increase with increasing radiation dose. The percentage of giant cells found in non-irradiated control animals is $0 \cdot 1$ per cent. Only the giant cells were presented in the histograms. The percentages of giant cells were calculated from 1,000 cels measured for non-irradiated control

and none over 130 units. In the irradiated animals, the giant cells not only increased in number rapidly but also gradually expanded its ranges to higher values on the dri. mass scale as the radiation dose increased. The percentages of giant cells with lower dry mass values were generally higher than those of the cells with higher dry mass values. The changes in the distribution of the giant cells are obviously related to the dose. For easy comparison, the distribution changes were illustrated in the histograms (Fig. 1).

Two factors contributed to the changes of giant cell distribution, namely, the increase in the number of giant cells and the increase in the dry mass of individual giant cells. The increase in number of the giant cells can be expressed as increase in percentage of the giant cells among the 1,000 cells measured from the surviving cell population for each dose, while the increase in dry mass of the individual giant cells can be expressed as an increase in mean dry mass per cell of the giant cell population.

Changes in mean dry mass per cell of the surviving giant cell population. From the fact that the giant cells showed it gradual spread towards the higher dry mass values in the increasing radiation doses as observed in the histograms (Fig. 1), one can almost predict that the mean dry mass of the giant cells will show a corresponding increase. When the mean dry mass of the giant cells for all the radiation doses as well as that of the non-irradiated control were calculated and plotted against the radiation doses in a curve, it became clear that the increase in mean dry mass per cell with the increasing radiation doses was approximately linear up to a limit somewhere between 1,000 and $1,500 \mathrm{r}$. (Fig. 2). The linearity of the curvo will probably improve with much larger coll samples 


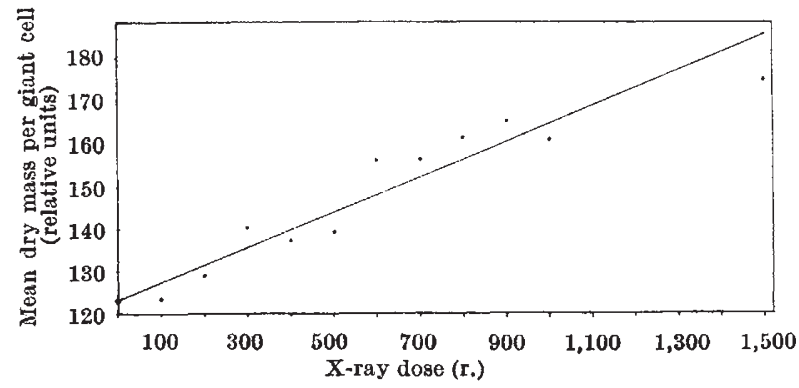

Fig. 2. Increase in mean dry mass per cell of the giant cell population of mouse bone marrow as plotted against increasing $\mathbf{X}$-ray doses is

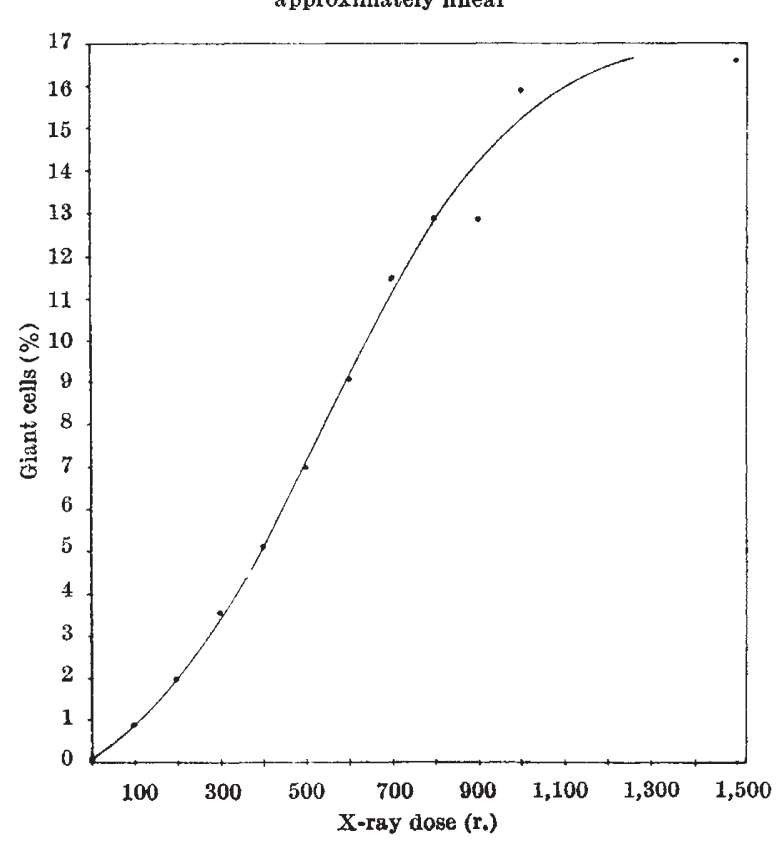

Fig. 3. Increase in the percentage of giant cells in the surviving marrow cell population of the mouse against the increasing $X$-ray doses result in a sigmold curve. The middle portion of the curve between $400 \mathrm{r}$. and $800 \mathrm{r}$. Is almost linear

measured. Thus the post-irradiational increase in mean dry mass per giant cell is also related to the dose.

Increase in percentages of giant cells in the surviving cell population. Another phenomenon related to the dose is the increase in percentages of giant cells in the surviving cell population which was demonstrated in both Puck's work ${ }^{5}$ and ours. A gradual increase in the number of the giant cells as the radiation dose increased was clearly noticeable when the histograms of the giant cell distribution (Fig. 1) were compared. This gradual increase can be more clearly elucidated by plotting the percentages of giant cells of the non-irradiated control and of the irradiated animals against the radiation doses (Fig. 3 ). This results in a sig. moid curve. The middle portion of the curve from 400 to $800 \mathrm{r}$. is almost linear. The dose $400 \mathrm{r}$. is $L D_{2}$, very close to the non-lethal dose $\left(L D_{0}\right)$, and the dose $800 \mathrm{r}$. coincides with $L D_{100}$. The increase of the giant cells is slow at the lower dose-levels but becomes faster at the 300-r. level; and a subsequent slowing down appeared at the last portion of the curve. This slowing down is probably due to the death of some giant cells at the higher dose-levels. The increase of the giant cells in the irradiated populations over that of the non-irradiated control is $\mathbf{5 2}$ times for $400 \mathrm{r}, 129$ times for $800 \mathrm{r}$. and 166 times for $1,500 \mathrm{r}$.

An increase in the size of cells following irradiation was observed in various organisms as well as mouse and human tumours in the late twenties through the early forties ${ }^{6-9}$. The appearance of radiation-induced giant cells in the animal bone marrow was first reported by Bloom in 1948 (ref. 10). The formation of the giant cells following irradia- tion was the result of mitotic inhibition without a corresponding inhibition in RNA and protein synthesis 11,12. Puck found that, after X-irradiation, when the HeLa cells were plated, in tissue culture, the proportion of giant cells in the cells of the abortive colonies increased with the increase of the X-ray dose ${ }^{5}$. Cell death without any subsequent cell division following irradiation, however, occurred only at dose-levels above $600 \mathrm{r}$. Our results show that not only the percentage of giant cells in the surviving cell population increases with the increase of the radiation dose; the giant cell distribution pattern and the mean dry mass per giant cell are also related to the dose. The increase in percentages of giant cells seems to be the result of the fact that more cells are affected by a higher radiation dose in their mitotic process, while the increase in mean dry mass per giant cell can be explained by the increasing duration of mitotic inhibition of the higher radiation doses. It is a well-established fact that the duration of mitotic inhibition increases with increasing dose of irradiation ${ }^{13}$. The changes in the percentages of giant cells and the changes in the dry mass of the individual cells, together with the possibility of the death of some giant cells at higher dose-levels, contributed to the changes in the giant cell distribution.

Whether any radiation-induced death of the marrow cells in the sense of complete cessation of all the biological activities with subsequent disappearance from the population within $24 \mathrm{~h}$ following irradiation at dose-levels no greater than $600 \mathrm{r}$. may occur is open to question in the light of Puck's findings. If mammalian cells in tissue culture do not die without at least one or two cell divisions following direct exposure to radiation at the 600-r. level, one would tend to believe that marrow cells subjected to in vivo irradiation at levels of $600 \mathrm{r}$. will probably not die in statistically significant numbers. Thus cell death may have played little part in the changes we found in our results, at least not at the 600-r. level or below. At any rate, our concern is the relationship between the radiation doses and changes in the giant cells of the surviving cell population as an index to the degree of radiation-caused marrow injury. Whether or not any cell death might have occurred is of no significance.

These findings may have value in the estimation of the extent of radiation injury to the bone marrow and, accordingly, to the prognosis for a patient. Inasmuch as the response of individuals to a given dose of radiation differs greatly, knowledge of the dose a patient receives is helpful but far from being safe.in permitting evaluation of the prognosis. A direct examination of the patient's response following the exposure is, therefore, of primary importance. This technique may offer possibilities as an aid in such investigations. The difficulty involved in the application of this technique for this type of study is that it is slow and tedious. With the information from our findings, we are at present exploring the possibilities of using much more rapid methods, such as a Coulter counter, for the measurement of corresponding changes in the size of the giant cells, and immersion refractometer for the measurement of the changes in cell dry mass concentrations at a populational level after irradiation of measured intensity.

This work was supported by U.S. Public Health Service grants $A M 0-7067$ (01 and 02) and $A M-04188$ (03 and 04).

${ }^{1}$ Lee, H., and Richards, V., Nature, 194, 784 (1962).

\& Lee, H., Richards, V., and Maichle, M., Blood (in the press).

s Lee, H., Richards, V., and Klausner, C., Cancer Res., 20, 1415 (1960).

- Lee, H., Richards, V., and Furst, A., Cancer Res., 21, 1108 (1961).

- Puck, T. T., and Marcus, P. I., J. Exp. Med., 103, 653 (1956).

- Mottram, J. C., J. Roy, Micro. Soc., 46, 127 (1926).

'Mottram, J. C., Brit. J. Radiol., 32, 61 (1927).

- Luyet, B. J., Radiology, 18, 1019 (1932).

'Lea, D. E., Haines, R. B., and Coulson, C. A., Proc. Roy. Soc., B, 123, 1 (1937).

${ }^{10}$ Bloom, W. (edit.), Histopathology of Irradiation from External and Internal Sources (McGraw-Hill, New York, 1948).

"1 Klein, G., and Forssberg, A., Exp. Cell Res., 6, 211 (1954).

${ }_{12}$ Caspersson, T., Kletn, E., and Ringertz, N. R., Cancer Res., 18, 857 (1958).

${ }^{18}$ Lea, D. E., Actions of Radiations on Living Cells, second ed., 282 (Camb. Univ. Press, 1956). 